\title{
Redeposition in plasma-assisted atomic layer deposition : silicon nitride film quality ruled by the gas residence time
}

Citation for published version (APA):

Knoops, H. C. M., de Peuter, K., \& Kessels, W. M. M. (2015). Redeposition in plasma-assisted atomic layer deposition : silicon nitride film quality ruled by the gas residence time. Applied Physics Letters, 107, 014102. https://doi.org/10.1063/1.4926366

DOI:

$10.1063 / 1.4926366$

Document status and date:

Published: 01/01/2015

Document Version:

Publisher's PDF, also known as Version of Record (includes final page, issue and volume numbers)

Please check the document version of this publication:

- A submitted manuscript is the version of the article upon submission and before peer-review. There can be important differences between the submitted version and the official published version of record. People interested in the research are advised to contact the author for the final version of the publication, or visit the $\mathrm{DOI}$ to the publisher's website.

- The final author version and the galley proof are versions of the publication after peer review.

- The final published version features the final layout of the paper including the volume, issue and page numbers.

Link to publication

\section{General rights}

Copyright and moral rights for the publications made accessible in the public portal are retained by the authors and/or other copyright owners and it is a condition of accessing publications that users recognise and abide by the legal requirements associated with these rights.

- Users may download and print one copy of any publication from the public portal for the purpose of private study or research.

- You may not further distribute the material or use it for any profit-making activity or commercial gain

- You may freely distribute the URL identifying the publication in the public portal.

If the publication is distributed under the terms of Article 25fa of the Dutch Copyright Act, indicated by the "Taverne" license above, please follow below link for the End User Agreement:

www.tue.nl/taverne

Take down policy

If you believe that this document breaches copyright please contact us at:

openaccess@tue.nl

providing details and we will investigate your claim. 


\section{AIP Aponed phy is

\section{Redeposition in plasma-assisted atomic layer deposition: Silicon nitride film quality ruled by the gas residence time}

Harm C. M. Knoops, K. de Peuter, and W. M. M. Kessels

Citation: Applied Physics Letters 107, 014102 (2015); doi: 10.1063/1.4926366

View online: http://dx.doi.org/10.1063/1.4926366

View Table of Contents: http://scitation.aip.org/content/aip/journal/apl/107/1?ver=pdfcov

Published by the AIP Publishing

\section{Articles you may be interested in}

Use of B2O3 films grown by plasma-assisted atomic layer deposition for shallow boron doping in silicon J. Vac. Sci. Technol. A 33, 031512 (2015); 10.1116/1.4917552

Low temperature hydrogen plasma-assisted atomic layer deposition of copper studied using in situ infrared reflection absorption spectroscopy

J. Vac. Sci. Technol. A 32, 01A108 (2014); 10.1116/1.4831915

Substrate-biasing during plasma-assisted atomic layer deposition to tailor metal-oxide thin film growth J. Vac. Sci. Technol. A 31, 01A106 (2013); 10.1116/1.4756906

In situ diagnostics for studying gas-surface reactions during thermal and plasma-assisted atomic layer deposition J. Vac. Sci. Technol. A 30, 01A158 (2012); 10.1116/1.3670404

Growth mechanism and diffusion barrier property of plasma-enhanced atomic layer deposition Ti-Si-N thin films J. Vac. Sci. Technol. B 24, 1327 (2006); 10.1116/1.2198846

Frustrated by

old technology?

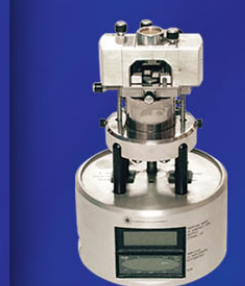

Is your AFM dead and can't be repaired?

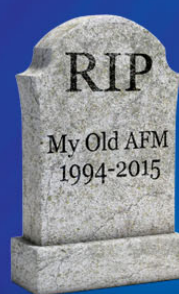

Sick of bad customer support?

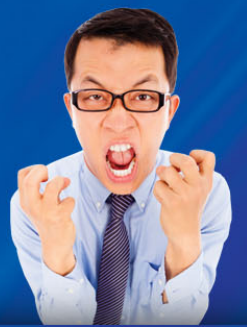

It is time to upgrade your AFM Minimum \$20,000 trade-in discount for purchases before August 31st

Asylum Research is today's technology leader in AFM 


\title{
Redeposition in plasma-assisted atomic layer deposition: Silicon nitride film quality ruled by the gas residence time
}

\author{
Harm C. M. Knoops, ${ }^{1,2, a)}$ K. de Peuter, ${ }^{1}$ and W. M. M. Kessels ${ }^{1, a)}$ \\ ${ }^{1}$ Department of Applied Physics, Eindhoven University of Technology, P.O. Box 513, 5600 MB Eindhoven, \\ The Netherlands \\ ${ }^{2}$ Oxford Instruments Plasma Technology, North End, Bristol BS49 4AP, United Kingdom
}

(Received 5 May 2015; accepted 25 June 2015; published online 7 July 2015)

\begin{abstract}
The requirements on the material properties and growth control of silicon nitride $\left(\mathrm{SiN}_{x}\right)$ spacer films in transistors are becoming ever more stringent as scaling of transistor structures continues. One method to deposit high-quality films with excellent control is atomic layer deposition (ALD). However, depositing $\mathrm{SiN}_{x}$ by ALD has turned out to be very challenging. In this work, it is shown that the plasma gas residence time $\tau$ is a key parameter for the deposition of $\mathrm{SiN}_{x}$ by plasmaassisted ALD and that this parameter can be linked to a so-called "redeposition effect". This previously ignored effect, which takes place during the plasma step, is the dissociation of reaction products in the plasma and the subsequent redeposition of reaction-product fragments on the surface. For $\mathrm{SiN}_{x}$ ALD using $\mathrm{SiH}_{2}\left(\mathrm{NH}^{t} \mathrm{Bu}\right)_{2}$ as precursor and $\mathrm{N}_{2}$ plasma as reactant, the gas residence time $\tau$ was found to determine both $\mathrm{SiN}_{x}$ film quality and the resulting growth per cycle. It is shown that redeposition can be minimized by using a short residence time resulting in high-quality films with a high wet-etch resistance (i.e., a wet-etch rate of $0.5 \mathrm{~nm} / \mathrm{min}$ in buffered HF solution). Due to the fundamental nature of the redeposition effect, it is expected to play a role in many more plasmaassisted ALD processes. (C) 2015 AIP Publishing LLC. [http://dx.doi.org/10.1063/1.4926366]
\end{abstract}

Silicon nitride $\left(\mathrm{SiN}_{x}\right)$ is one of the most widely used thin-film materials in many areas such as semiconductor technology, photovoltaics, and displays-due to its unique combination of optical, electrical, mechanical, and chemical properties. ${ }^{1}$ One of its key applications in semiconductor technology is as spacer films in transistors where the $\mathrm{SiN}_{x}$ serves multiple roles such as a barrier film and masking material. For this application, the requirement of uniform material quality and film thickness throughout the device, independent of transistor pitch, is becoming ever more rigorous as miniaturization of the transistor structures continues. One method to deposit high-quality thin films with excellent control is atomic layer deposition (ALD). However, despite the many advances in ALD, depositing $\operatorname{SiN}_{x}$ by ALD has turned out to be very challenging. ${ }^{1-6}$ This is especially the case when low impurity levels and low wet-etch rates are required, combined with the need to be deposited at low substrate temperatures $\left(<400^{\circ} \mathrm{C}\right)$ from halide-free precursors. ${ }^{1}$ Similar as for other nitride ALD processes, plasmas can be used during the reactant step to increase the surface reactivity. ${ }^{7}$ Nonetheless, even with the high reactivity of the plasma, long plasma times are required to avoid high impurity contents. Other process parameters which are generally identified as key for ALD of nitrides are the substrate temperature and the plasma gas pressure. ${ }^{7}$ However, little is known about the underlying physical processes that determine the film quality. Hence, research efforts are carried out to identify the most important parameters and underlying processes and to find routes towards better nitride ALD processes.

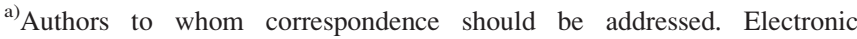
addresses: h.c.m.knoops@tue.nl and w.m.m.kessels@tue.nl
}

In this letter, we will show that the gas residence time $\tau$ during the plasma step is a key parameter for depositing high-quality $\mathrm{SiN}_{x}$ by plasma-assisted ALD and that this parameter can be linked to the so-called "redeposition effect". This effect is the dissociation in the plasma of reaction products released from the surface and the subsequent redeposition of reaction-product fragments on the surface. These fragments can be incorporated in the film, increasing impurity levels and affecting the growth of the $\operatorname{SiN}_{x}$ films. Due to its general nature, it is expected that the redeposition effect is of significance for a wide range of plasma-assisted ALD processes.

The $\mathrm{SiN}_{x}$ ALD process used in this work employed $\mathrm{SiH}_{2}\left(\mathrm{NH}^{t} \mathrm{Bu}\right)_{2}$ (BTBAS) as precursor and $\mathrm{N}_{2}$ plasma as reactant. The details of the process will be reported in a separate publication, ${ }^{8}$ and therefore, only the general characteristics are discussed here. Briefly, the depositions were carried out using a remote plasma ALD reactor (Oxford Instruments FlexAL $\left.{ }^{\circledR}\right){ }^{9}$ The precursor $\mathrm{SiH}_{2}\left(\mathrm{NH}^{t} \mathrm{Bu}\right)_{2}$ (BTBAS, purity $\geq 98.5 \%$, Air Products Inc.) was held at a bubbler temperature of $50^{\circ} \mathrm{C}$ and vapor drawn into the reactor. The reactor was equipped with a remote inductively coupled (ICP) plasma generator, which was operated at $600 \mathrm{~W}$ at $13.56 \mathrm{MHz}$ using $\mathrm{N}_{2}$ (purity 99.9999\%) and Ar (purity 99.999\%) as plasma gasses. A butterfly valve controlled the effective pumping speed. During precursor dosing and the subsequent reaction step, this valve was set to $10^{\circ}$ to maximize precursor usage. During purging steps, the valve was set to $90^{\circ}$ valve position for maximum pumping. Based on the saturation curves determined for precursor dose and plasma exposure, ${ }^{8}$ the following recipe was chosen as a standard: $1 \mathrm{~s}$ delivery line purge, $150 \mathrm{~ms}$ BTBAS dose time, $3 \mathrm{~s}$ reaction time, $1 \mathrm{~s}$ precursor purge time, $2 \mathrm{~s}$ pre-plasma time, $10 \mathrm{~s}$ plasma exposure time 
TABLE I. The growth per cycle (GPC), refractive index at $2 \mathrm{eV}$, and composition of $\mathrm{SiN}_{x}$ films of $\sim 40 \mathrm{~nm}$ thickness deposited at various substrate table temperatures and plasma conditions. Typical error margins are indicated for the first value in each column. A dash indicates "not measured." A change in used parameters compared to the first line is indicated in bold.

\begin{tabular}{|c|c|c|c|c|c|c|c|c|}
\hline \multirow{2}{*}{$\begin{array}{l}\text { Table } \\
\text { temperature }\left({ }^{\circ} \mathrm{C}\right)\end{array}$} & \multirow{2}{*}{$\begin{array}{c}\text { Plasma } \\
\text { pressure (mTorr) }\end{array}$} & \multirow{2}{*}{$\begin{array}{l}\text { Plasma } \\
\text { time (s) }\end{array}$} & \multirow{2}{*}{$\begin{array}{l}\text { GPC } \\
(\AA)\end{array}$} & \multirow{2}{*}{$\begin{array}{l}\text { Refractive } \\
\text { index }\end{array}$} & \multicolumn{3}{|c|}{ XPS } & \multirow{2}{*}{$\begin{array}{c}\text { ERD } \\
{[\mathrm{H}] \text { at. \% }}\end{array}$} \\
\hline & & & & & $\mathrm{N} / \mathrm{Si}$ ratio & {$[\mathrm{C}]$ at. $\%$} & {$[\mathrm{O}]$ at. $\%$} & \\
\hline 200 & 40 & 10 & $0.32 \pm 0.02$ & $1.83 \pm 0.03$ & $1.7 \pm 0.1$ & $9 \pm 1$ & $5 \pm 1$ & $10.9 \pm 0.5$ \\
\hline 200 & 40 & 15 & 0.28 & 1.86 & 1.7 & 8 & 5 & 9.6 \\
\hline 200 & 13 & 10 & 0.24 & 1.91 & 1.6 & 6 & 5 & $\ldots$ \\
\hline 400 & 40 & 10 & 0.16 & 1.96 & 1.5 & 2 & 4 & 5.4 \\
\hline
\end{tabular}

using $100 \mathrm{sccm} \mathrm{N}_{2}$ flow at $40 \mathrm{mTorr}$ plasma pressure, and $1 \mathrm{~s}$ plasma purge time. These settings were used unless mentioned otherwise. The experiments were carried out at various substrate table temperatures ranging from $200^{\circ} \mathrm{C}$ up to $400{ }^{\circ} \mathrm{C}$.

To first understand the general behavior of the $\operatorname{SiN}_{x}$ ALD process, the material properties as a function of temperature and plasma conditions are considered as shown in Table I. All conditions result in $\mathrm{SiN}_{x}$ films with some $\mathrm{C}, \mathrm{O}$, and $\mathrm{H}$ impurities. There is a small decrease in $\mathrm{C}$ and $\mathrm{H}$ content with plasma exposure time for deposition at $200^{\circ} \mathrm{C}$. Deposition at a lower pressure of $13 \mathrm{mTorr}$ instead of $40 \mathrm{mTorr}$ shows that a decrease in plasma pressure can further improve the material properties although there is still a measurable $\mathrm{C}$ impurity content. At a high table temperature of $400^{\circ} \mathrm{C}$, the properties are closest to those of low impurity, stoichiometric silicon nitride. Next, we will illustrate how the persistence of the $\mathrm{C}$ content at a deposition temperature of $200{ }^{\circ} \mathrm{C}$ is caused by dissociation of reaction products in the plasma, and redeposition of $\mathrm{C}$-containing species onto the surface.

The first indication of redeposition comes from the optical emission from the plasma during the ALD cycle. During the plasma step, the plasma not only consists of the feed gas but also of reaction products released from the surface. These reaction products will be dissociated in the plasma as long as they are present. This can be observed in Fig. 1(a) which shows that the plasma feedstock species yield a relatively constant emission signal while the signal from the dissociated reaction products (e.g., $\mathrm{CN}$ emission) is timedependent. The fragments of the reaction products can redeposit on the surface as illustrated by the schematic in Fig. 1(b). The time for interaction between the reaction products and the plasma depends on the gas residence time $\tau$, which is a measure of how long species remain in the reaction chamber before being flushed out. The residence time is given by the expression $\tau=V / q$, where $V$ is the effective volume of the reactor and $q$ is the volumetric flow rate through that volume (or effective pumping speed). ${ }^{10}$ The larger $q$, the faster species are flushed out of the reactor. The presence of $\mathrm{CN}$ emission and also the presence of species, such as $\mathrm{HCN}$, $\mathrm{C}_{3} \mathrm{H}_{8}$, and $\mathrm{C}_{2} \mathrm{~N}_{2}$ (not shown) as measured by mass spectrometry, show the interaction of the plasma with the reaction products and the formation of new species. Note that redeposition processes and removal of redeposition from the surface are continuous. Species that redeposit on the surface can be again removed by the plasma, but once in the plasma, they can again dissociate and redeposit as long as they are not flushed out.
A similar effect was proposed in our previous work for plasma-assisted ALD of $\mathrm{TaN}_{x}$ using $\mathrm{Ta}(\mathrm{NMe})_{5}$ as precursor and $\mathrm{H}_{2}$ plasma as reactant. ${ }^{11}$ For this process, a slow removal of $\mathrm{C}$ impurities from the film during the plasma exposure

(a)

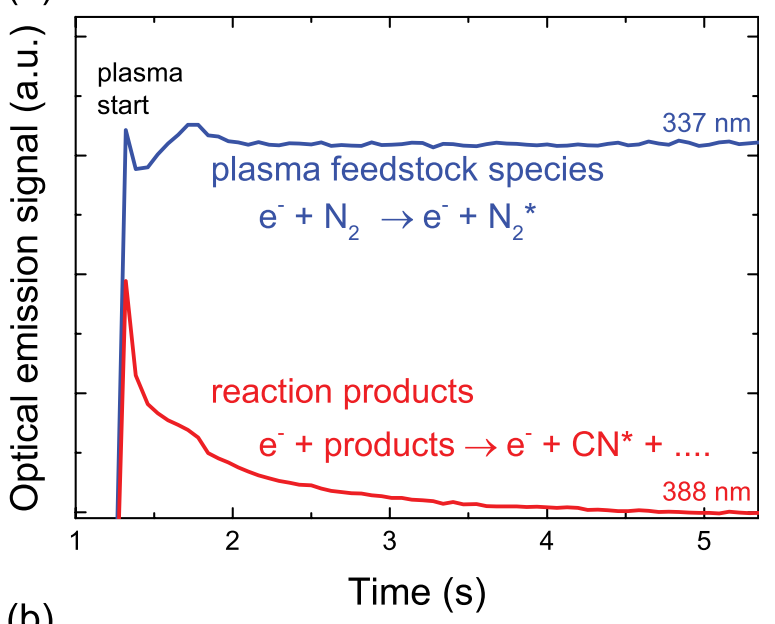

(b)

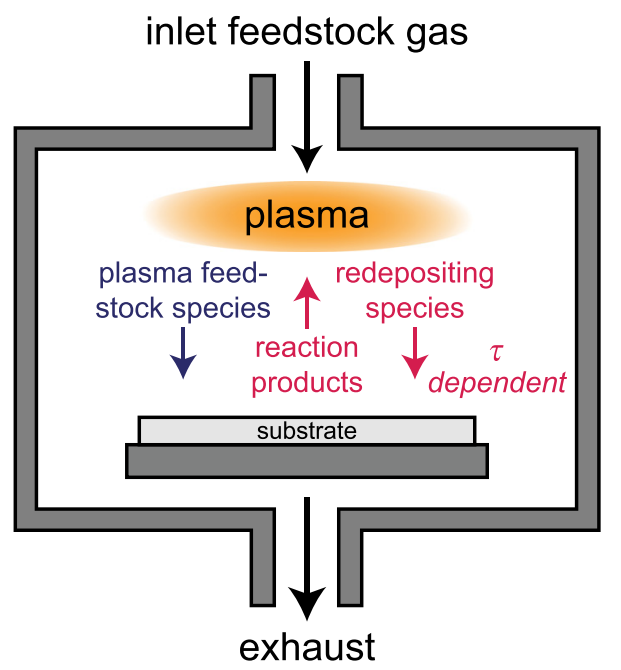

FIG. 1. (a) Optical emission signals during a $100 \mathrm{mTorr}^{\mathrm{N}} \mathrm{N}_{2}$ plasma exposure step following the precursor exposure in the cycle. A constant signal is observed for plasma feedstock species (here illustrated for $\mathrm{N}_{2}{ }^{*}$ emission at $337 \mathrm{~nm}\left(\mathrm{C}^{3} \prod_{u} \rightarrow \mathrm{B}{ }^{3} \prod_{g}\right)$ ), and a time-dependent signal is observed for dissociated reaction products (here illustrated for $\mathrm{CN}^{*}$ emission at $388 \mathrm{~nm}$ $\left.\left(\mathrm{B}^{2} \sum \rightarrow X^{2} \sum\right)\right) .{ }^{14}$ Note that the emission fluctuation during the start-up of the plasma exposure can be assigned due to plasma matching effects which indicate the large influence of the released reaction products on the plasma composition. (b) Schematic illustration of the redeposition process. During the plasma exposure step, precursor ligands are liberated from the surface and enter the gas phase. These reaction products can dissociate in the plasma (e.g., by electron impact) leading to reactive species which can redeposit on the surface. The extent of the redeposition will depend on the gas residence time $\tau$. 
was explained by dissociation of reaction products (such as $\mathrm{CH}_{4}$ ) in the plasma, and their subsequent redeposition.

To clearly demonstrate the presence of the redeposition effect, several experiments with different $\tau$ values but constant plasma exposure times were performed for the $\mathrm{SiN}_{x}$ ALD process. In these experiments, $\tau$ was varied by changing the total gas flow and the set pressure (controlled by the butterfly valve). High gas flows were achieved by adding Ar to the $\mathrm{N}_{2}$ plasma gas. A clear effect of redeposition is expected at $200^{\circ} \mathrm{C}$ where a change in plasma pressure showed a large difference in refractive index as was shown in Table I. Figure 2(a) shows that for films deposited at $200{ }^{\circ} \mathrm{C}$ using $10 \mathrm{~s}$ plasma exposure and with various total gas flows and gas pressures, the refractive index increases with decreasing $\tau$. Note that other effects associated with low pressure, such as a change in energy of ions impinging on the surface, appear secondary to the effect of low residence time and do not show a one-to-one influence on the refractive index. For instance, a pressure of 20 mTorr at a gas flow of $40 \mathrm{sccm}$ leads to a lower refractive index than 40 mTorr at $100 \mathrm{sccm}$, even though the ion energies will be higher at 20 mTorr. Apparently, the ions, with energies estimated at $<15 \mathrm{eV}$ for the entire pressure range, have a much smaller effect than the residence time. ${ }^{7,12}$ A similar trend with $\tau$ can

(a)
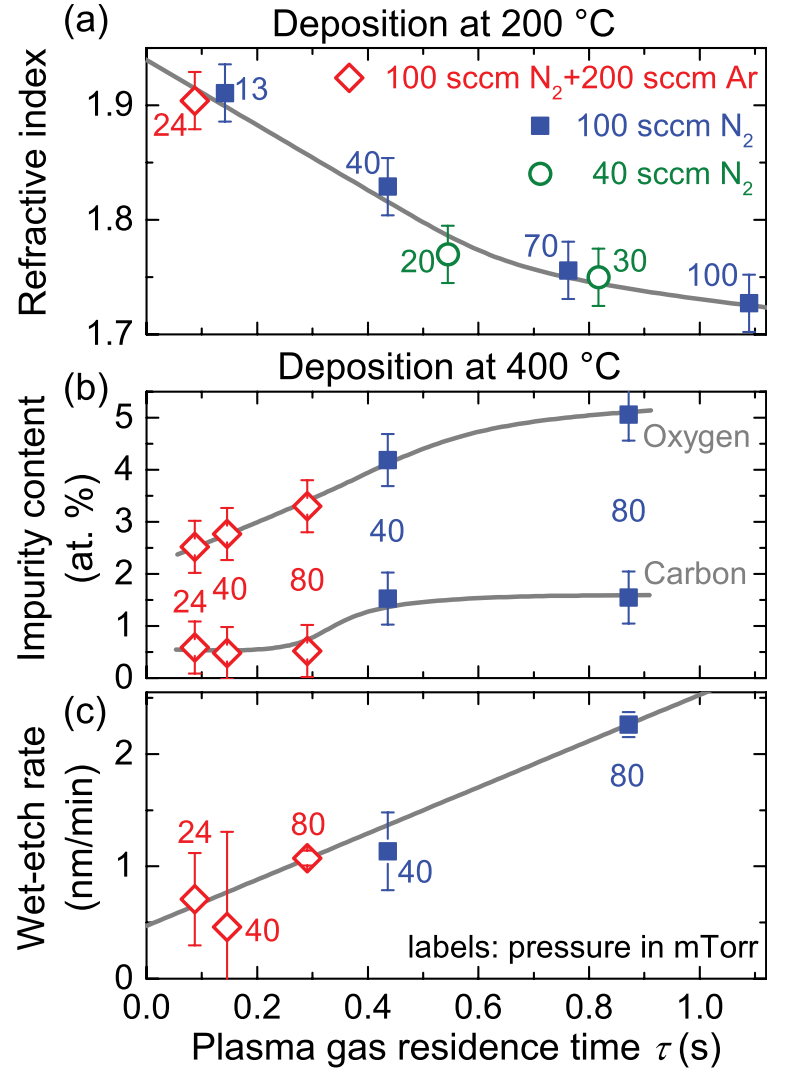

FIG. 2. Material properties as a function of plasma gas residence time $\tau$ for $\mathrm{SiN}_{x}$ films deposited at $200^{\circ} \mathrm{C}$ and $400^{\circ} \mathrm{C}$ using $10 \mathrm{~s} \mathrm{~N}_{2}$ plasma exposure at various total gas flows and plasma gas pressures. The films had a thickness of $20 \mathrm{~nm}$ or higher. (a) Refractive index at $2 \mathrm{eV}$ for $\mathrm{SiN}_{x}$ films deposited at $200^{\circ} \mathrm{C}$. (b) Oxygen and carbon impurity content and (c) wet-etch rates in BHF for $\mathrm{SiN}_{x}$ films deposited at $400^{\circ} \mathrm{C}$. For the buffered etch, a stock solution was used of a 7:1 volume ratio of $40 \% \mathrm{NH}_{4} \mathrm{~F}$ in water and $49 \% \mathrm{HF}$ in water. The various gas flows are indicated in the legend and the data points are labeled with the associated gas pressures. The lines serve as a guide to the eye. be observed for the impurity levels for films deposited at $400{ }^{\circ} \mathrm{C}$ as shown in Fig. 2(b), even though the effect on refractive index is relatively small at this temperature (data not shown). Here, both the oxygen and carbon impurity levels decrease monotonically with decreasing $\tau$, while the material properties do not show a clear dependence on pressure. Note that besides the faster removal of redepositing species at short $\tau$ values, also the faster removal of background impurities could contribute to lower oxygen levels. For instance, background water released from the reactor walls is removed faster at short $\tau$ values, leading to lower water levels during the plasma exposure. The improvement of the material quality at short $\tau$ values can have a direct influence on the application of these films. Figure 2(c) shows for instance that the wet-etch rates of the films correlate clearly with $\tau$. The wetetch rate is a key parameter for several applications of ALD $\mathrm{SiN}_{x}$ films including the application of $\mathrm{SiN}_{x}$ as spacer materials in transistors. ${ }^{13}$

Another consequence of the redeposition can be observed for the growth per cycle (GPC), especially for moderate to low temperatures where refractive index and film purity are affected most. Figure 3(a) shows that the growth per cycle (GPC) at $200^{\circ} \mathrm{C}$ shows an unusual trend as a function
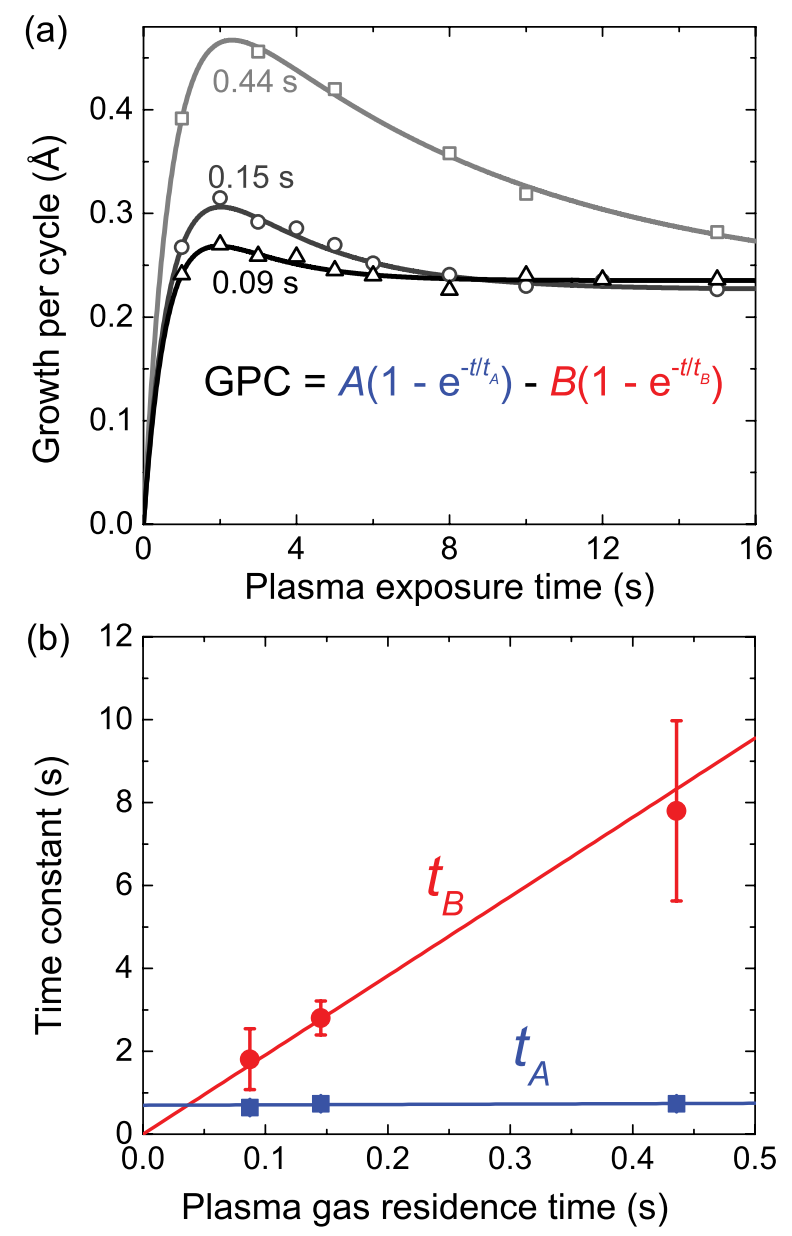

FIG. 3. (a) Growth per cycle (GPC) as a function of $\mathrm{N}_{2}$ plasma exposure time for $\mathrm{SiN}_{x}$ films deposited at $200^{\circ} \mathrm{C}$ and three different plasma gas residence times $\left(\tau=0.44 \mathrm{~s}\right.$, for $100 \mathrm{sccm} \mathrm{N} \mathrm{N}_{2}$ at $40 \mathrm{mTorr} ; \tau=0.15 \mathrm{~s}$, for 100 $\mathrm{sccm} \mathrm{N_{2 }}+200 \mathrm{sccm}$ Ar at $40 \mathrm{mTorr}$; and $\tau=0.09 \mathrm{~s}$, for $100 \mathrm{sccm} \mathrm{N}_{2}+200$ $\mathrm{sccm} \mathrm{Ar}$ at $24 \mathrm{mTorr}$ ). The lines are fits to the expression given in (a). (b) The values of the time constants $t_{A}$ and $t_{B}$ extracted from the fits in (a) as a function of residence time $\tau$. The solid lines are linear fits to the data points. 
of plasma exposure time. First, there is a rapid increase in GPC and then a slow decrease. When comparing curves for plasmas with different $\tau$ values, it becomes clear that the overshoot in GPC can be assigned to redeposition. The contribution by redeposition decreases when using lower $\tau$ values, and the effective rate of removal of the redeposition (the decrease of the GPC after the overshoot) is faster as well. The trend of the GPC with plasma exposure time can be fitted with a relatively simple two-term exponential decay function, ${ }^{10}$ where the first part (A) of the function can be assigned to the normal ALD behavior during the plasma exposure step (i.e., creation of reactive sites for precursor adsorption), and the second part (B) of the function can be assigned to redeposition (i.e., the combined effect of redeposition of dissociated species and the subsequent removal again from the surface by the plasma). As expected, for lower $\tau$ values this component $B$ is strongly reduced because less redeposition takes place under these conditions in the first place. When the GPC curves are fitted for three $\tau$ values, the resulting time constants can be plotted as a function of $\tau$ (Fig. 3(b)). The time constant of component $\mathrm{A}$ does not depend on $\tau$, while the time constant of component $\mathrm{B}$ increases linearly with $\tau$, which is directly in agreement with the mechanism illustrated by the schematic of Fig. 1(b). This means that the rate of the redeposition component scales with $\tau$. The time constant of component A, in turn, purely depends on the flux of reactive species. Note that one has to consider changes in plasma parameters when varying the residence time. The fact that $t_{A}$ is constant shows that our method of varying $\tau$ (adding gas and changing pumping speed) has minimal effect on initial saturation and therefore on the flux of reactive species. In general, the effect of $\tau$ on the GPC as function of plasma exposure shows that redeposition processes make the resulting film thickness more dependent on the received flux of reactive species. Therefore, even after initial saturation (described by component A), variations in flux over the wafer and in trench structures can have an effect on film uniformity and conformality due to redeposition.

In conclusion, redeposition has been identified as a key process for plasma-assisted ALD of $\mathrm{SiN}_{x}$ determining both the film growth and the material quality. Redeposition can be controlled by the gas residence time $\tau$ during the plasma step as it directly determines how fast the reaction products are flushed out of the reactor. The faster the reaction products are flushed out, the less chance they have that they redeposit on the surface. This will generally lead to higher film quality as shown by higher refractive index values and lower impurity levels. Consequently, for low $\tau$ values, $\operatorname{SiN}_{x}$ films with low wet-etch rates of $0.5 \mathrm{~nm} / \mathrm{min}$ in buffered HF solution were obtained. Besides obtaining low $\tau$ values by only increasing the effective pumping speed, which would lead to low pressures, $\tau$ can also be relatively low even at moderate pressures when using high gas flows. These conditions could be favorable for sensitive devices where low pressure plasmas can lead to plasma damage due to ion bombardment or energetic plasma radiation. Since ligands are removed during the plasma step for basically all plasma-assisted ALD processes, the dissociation of these reaction products in the plasma and the subsequent redeposition could play a role in a wide range of ALD processes.

The authors would like to thank Maarten van Drunen and Dr. Anne-Marije Andringa for refractive index measurements and deposition of samples. The research of one of the authors (WMMK) has been made possible by the Dutch Technology Foundation STW and the Netherlands Organization for scientific Research (NWO, VICI programma, 10817).

${ }^{1}$ W. Jang, H. Jeon, C. Kang, H. Song, J. Park, H. Kim, H. Seo, M. Leskela, and H. Jeon, Phys. Status Solidi A 211, 2166 (2014).

${ }^{2}$ H. Goto, K. Shibahara, and S. Yokoyama, Appl. Phys. Lett. 68, 3257 (1996).

${ }^{3}$ K. Park, W.-D. Yun, B.-J. Choi, H.-D. Kim, W.-J. Lee, S.-K. Rha, and C. O. Park, Thin Solid Films 517, 3975 (2009).

${ }^{4}$ S. W. King, J. Vac. Sci. Technol. A 29, 041501 (2011).

${ }^{5}$ R. A. Ovanesyan, D. M. Hausmann, and S. Agarwal, ACS Appl. Mater. Interfaces 7, 10806 (2015).

${ }^{6}$ S. Riedel, J. Sundqvist, and T. Gumprecht, Thin Solid Films 577, 114 (2015).

${ }^{7}$ H. B. Profijt, S. E. Potts, W. M. M. Kessels, and M. C. M. van de Sanden, J. Vac. Sci. Technol. A 29, 50801 (2011).

${ }^{8}$ H. C. M. Knoops, E. M. J. Braeken, K. de Peuter, S. E. Potts, S. Haukka, V. Pore, and W. M. M. Kessels, "Atomic Layer Deposition of Silicon Nitride from Bis(tert-butylamino)silane and $\mathrm{N}_{2}$ Plasma," (to be published).

${ }^{9}$ S. B. S. Heil, J. L. van Hemmen, C. J. Hodson, N. Singh, J. H. Klootwijk, F. Roozeboom, M. C. M. van de Sanden, and W. M. M. Kessels, J. Vac. Sci. Technol. A 25, 1357 (2007).

${ }^{10}$ See supplementary material at http://dx.doi.org/10.1063/1.4926366 for determination of plasma gas residence time and fitting of GPC as a function of plasma exposure time.

${ }^{11}$ H. C. M. Knoops, E. Langereis, M. C. M. van de Sanden, and W. M. M. Kessels, J. Vac. Sci. Technol. A 30, 01A101 (2012).

${ }^{12}$ H. B. Profijt, P. Kudlacek, M. C. M. van de Sanden, and W. M. M. Kessels, J. Electrochem. Soc. 158, G88 (2011).

${ }^{13}$ F. Koehler, D. H. Triyoso, I. Hussain, B. Antonioli, and K. Hempel, Phys. Status Solidi 11, 73 (2014).

${ }^{14}$ A. J. M. Mackus, S. B. S. Heil, E. Langereis, H. C. M. Knoops, M. C. M. van de Sanden, and W. M. M. Kessels, J. Vac. Sci. Technol. A 28, 77 (2010). 